\title{
MUC16 mucin (CA125) attenuates TRAlL-induced apoptosis by decreasing TRAIL receptor R2 expression and increasing c-FLIP expression
}

\author{
Isabelle Matte, Denis Lane, Marianne Boivin, Claudine Rancourt and Alain Piché*
}

\begin{abstract}
Background: MUC16 (CA125) is a large transmembrane mucin protein (> $200 \mathrm{kDa}$ ) aberrantly expressed in approximately $80 \%$ of human epithelial ovarian cancers (EOC). MUC16 expression in EOC cells is associated with increased tumorigenesis and inhibiton of genotoxic drug-induced apoptosis. However, the mechanism by which MUC16 mediates these effects is unknown. In the present study, we investigated the mechanisms by which MUC16 attenuates TRAIL-induced apoptosis.
\end{abstract}

Methods: MUC16 expression was down-regulated by stably expressing an anti-MUC16 single-chain antibody (scFv) targeted to the endoplasmic reticulum (ER), which prevents cell surface localization of MUC16 in OVCAR3 cells. We also generated a MUC16 C-terminal domain (MUC16CTD) construct that was stably expressed in MUC16 negative SKOV3 cells.

Results: We show that MUC16 attenuates apoptosis, activation of caspase-8 and mitochondria activation in EOC cells in response to TRAIL. MUC16 decreases TRAIL receptor R2 (DR5) expression and inhibits pro-caspase-8 activation at the death-inducing signaling complex (DISC). MUC16CTD expression is sufficient to attenuate the TRAIL signaling cascade. MUC16 knockdown decreases caspase-8 inhibitor cFLIP mRNA levels, increases cFLIP degradation, and consequently increases TRAIL-induced apoptosis. Down-regulation of cFLIP following treatment of MUC16-expressing OVCAR3 cells with CFLIP siRNA also increases TRAlL-induced apoptosis.

Conclusions: These findings indicate that MUC16 protects EOC cells against TRAlL-induced apoptosis through multiple mechanisms including the blockade of TRAIL R2 expression and the regulation of CFLIP expression at both the transcriptional and the protein level.

Keywords: MUC16/CA125, Mucins, Death receptors, TRAIL, Ovarian cancer, Apoptosis

\section{Background}

Apoptosis plays a critical role in cellular homeostasis and prevents the development of tumor cells. The apoptotic response of cells can be induced by the intrinsic and the extrinsic pathway, the former being mediated by the mitochondria and the latter activated by ligand stimulation of death receptors at the cell surface [1]. Death receptor ligands such as tumor necrosis factorrelated apoptosis-inducing ligand (TRAIL) trigger rapid apoptosis in vitro and in vivo in various tumor cell types

\footnotetext{
*Correspondence: alain.piche@usherbrooke.ca
Département de Microbiologie et Infectiologie, Faculté de Médecine et des

*Correspondence: alain.piche@usherbrooke.ca
Département de Microbiologie et Infectiologie, Faculté de Médecine et des sciences de la santé, Université de Sherbrooke, 3001, 12ième Avenue Nord, Sherbrooke, Québec J1H 5N4, Canada
}

[2-7]. TRAIL binds to death receptors, TRAIL-R1 (DR4) and -R2 (DR5), whose cytoplasmic death domain (DD) signals downstream caspase activation to mediate TRAILinduced apoptosis [8]. In contrast, TRAIL-R3, TRAIL-R4 and osteoprotegerin (OPG) act as decoy receptors [9-11]. Upon receptor activation, FADD and pro-caspase- 8 are recruited to form a death-inducing signaling complex (DISC) [12]. When recruited to the DISC, pro-caspase-8 becomes activated and subsequently activates downstream effectors caspases-3, -6 and -7 , leading to apoptosis. Procaspase-8 activation can directly result in cleavage of caspase- 3 to execute apoptosis (type I cells) or cleave Bid to produce a truncated form (tBid), which induces the release of cytochrome $\mathrm{c}$ from the mitochondria leading to 
caspase-9 and subsequent caspase- 3 activation (type II cells) as it is the case for EOC cells. The cellular FLICE inhibitory protein (cFLIP) regulates both recruitment and processing of pro-caspase- 8 within the DISC [13]. There are two major splice variants expressed in human cells, cFLIP $_{\mathrm{S}}(25 \mathrm{kDa})$ and $\mathrm{cFLIP}_{\mathrm{L}}(55 \mathrm{kDa})$ [14]. Both isoforms are able to block, although via different mechanisms, caspase- 8 activation within the DISC. Consequently, cFLIP isoforms are potent negative regulators of the TRAIL signaling cascade.

MUC16 mucin (CA125) is a large transmembrane glycoprotein that shares many characteristics of the membranebound mucin proteins [15-18]. Whereas MUC16 expression is found in the majority of EOC of serous type, it is not detected in normal ovarian epithelium [19]. The structure of MUC16 consists of an enormous N-terminal domain with more than 22,000 heavily glycosylated amino acid residues, a central domain containing up to 60 glycosylated repeat sequences constituting the characteristic tandem repeats of mucins and a C-terminal domain (CTD) [15-18]. The MUC16CTD anchors the protein at the cell surface and consists of a 229 amino acid extracellular region containing a potential proteolytic cleavage site, a 23 residue transmembrane domain, and a 31 amino acid cytoplasmic tail. MUC16 extracellular domain binds to mesothelin [20-22], galectin-3 [23] and Siglec-9 [24]. MUC16 may be involved in suppressing natural killer cell activity [25]. Expression of MUC16CTD in malignant cells enhances migration, invasion, tumor growth and metastasis whereas MUC16 knockdown completely abolishes tumor formation in vitro and in vivo [26]. MUC16 knockdown sensitizes ovarian cancer cells to apoptosis induced by genotoxic drugs [27]. The mechanisms by which the CTD of MUC16 mediates these biological effects are unknown.

In the present study, we show that MUC16 decreases TRAIL-R2 expression, increases cFLIP expression, blocks recruitment of caspase- 8 to the DISC, and consequently attenuates the activation of the TRAIL-induced apoptotic pathway.

\section{Methods}

\section{Cell lines}

The OVCAR3 and SKOV3 human ovarian cancer cell lines were obtained from the American Type Culture Collection (Manassas, VA). OVCAR3 cells were grown in RPMI 1640 (Wisent, St-Bruno, QC, Canada) supplemented with 20\% heat-inactivated FBS (Wisent), $2 \mathrm{mM}$ L-glutamine (Wisent), 100 units/ml penicillin, $100 \mu \mathrm{g} / \mathrm{ml}$ streptomycin and $10 \mu \mathrm{g} / \mathrm{ml}$ insulin, and maintained at $37^{\circ} \mathrm{C}$ in a humidified $5 \% \mathrm{CO}_{2}$ incubator. The SKOV3 cell line was maintained in DMEM/F12 (Wisent) supplemented with $10 \%$ heat-inactivated FBS, glutamine andantibiotics. OVCAR3 R350 cells are a TRAIL-resistant isogenic cell line that was obtained by exposing OVCAR3 cells to stepwise increases of TRAIL over 4 months. This cell line has been described previously [28]. The construction of the anti-MUC16 scFv has been previously described in detail [26,27]. Two independent stable OVCAR3 clones expressing the anti-MUC16 scFv (1:9\#7 scFv, 1:9\#9 scFv), and the control scFv (ctrl scFv) were generated by transfection of these plasmids into OVCAR3 cells and their validation has been described previously [26,27]. Derivation of MUC16CTD-expressing SKOV3 cells has also been previously described [26,27]. In this construct, MUC16CTD is tagged at the C-terminal with an His and a c-myc tag to allow easy detection of MUC16CTD expression.

\section{Reagents}

Recombinant human TRAIL was purchased from PeproTech, inc. (Rocky Hill, NJ). The TRAIL-R2 agonist antibody (clone 71903), the tetrapeptide caspase inhibitor, z-IETD-fmk, anti-XIAP and anti-caspase-8 antibodies were obtained from R\&D Systems (Minneapolis, MN). Anti-caspase-9, anti-caspase-3, anti-Bid, and anti-Bcl- $\mathrm{X}_{\mathrm{L}}$, anti-mouse HRP and anti-rabbit HRP antibodies were purchased from Cell Signaling (Beverly, MA). TRAILFlag and anti-TRAIL-R1 to R4 receptor antibodies used for flow cytometry were from Alexis Biochemicals (San Diego, CA). Anti-FADD and anti-TRAIL R2 used to perform Western blotting were from EMD Millipore (Etobicoke, ON, Canada). Anti-c-FLIP $\mathrm{L}_{\mathrm{L}}$ and anti-c-FLIP antibodies were purchased from Calbiochem (LaJolla, CA). Anti-Bcl-2 and anti-CA125 M11 antibodies were obtained from Dako (Burlington, ON, Canada) and antiCA125 OC125 antibody was from Zymed (South San Francisco, CA). XTT, phenazine methosulfate, propidium iodide, cycloheximide, anti-Flag M2 and anti-tubulin were from Sigma (Oakville, ON, Canada). Anti-Bax and antimyc-789 used for immunoprecipitation experiments were from Santa Cruz Biotechnology Inc. (Santa Cruz, CA). Anti-myc 9E10 antibody used for Western blot detection, real-time PCR Taqman Gene Expression Assay Master Mix, Flip primers for RT-PCR assays and Flip siRNA were from Life Technologies Inc (Burlington, ON, Canada). Anti-His antibody used for immunoprecipitation experiments was from Bioshop Canada (Burlington, ON). RNAse was obtained from Roche (Laval, QC, Canada).

\section{Cytotoxicity assays}

Cell viability was determined by the XTT assay. Briefly, cells were plated at 20,000 cells/well in 96-well plates. The next day, cells (confluence 60-70\%) were treated with human recombinant TRAIL or anti-TRAIL-R2 agonist antibody as indicated and incubated for $48 \mathrm{~h}$. In some experiments, synthetic caspase inhibitor $(25 \mu \mathrm{M}$ $\mathrm{z}$-IETD-fmk) was added $1 \mathrm{~h}$ before the addition of 25 $\mathrm{ng} / \mathrm{ml}$ of TRAIL. At the termination of the experiment, 
the culture media was removed and a mixture of PBS and fresh media (without phenol red) containing phenazine methosulfate and XTT was added for $30 \mathrm{~min}$. The absorbance of each well was determined using a microplate reader at $450 \mathrm{~nm}$ (TecanSunrise, Research Triangle Pack, $\mathrm{NC}$ ). The percentage of cell survival was defined as the relative absorbance of treated versus untreated cells. All assays were performed in triplicate and repeated three times.

\section{Apoptosis assays}

Caspase-3 fluorogenic protease assay was performed according the manufacturer's protocol (R\&D Systems, Minneapolis, MN). In brief, $3 \times 10^{6}$ cells were lysed in $250 \mu \mathrm{l}$ of cell lysis buffer, and total cell lysates were incubated with $50 \mu \mathrm{M}$ of DEVD-AFC substrate for $1 \mathrm{~h}$. Caspase-3 activity was measured on a Versa Fluor fluoremeter (BioRad, Hercules, CA). Protein concentration of the lysates was measured with Bio-Rad protein assay kit according to the manufacturer's recommendations.

To determine the sub-G0 DNA content, floating and adherent cells were harvested, washed with PBS/2\% FBS and fixed with cold ethanol for $2 \mathrm{~h}$. Cell pellets were resuspended, washed with PBS, filtered on nylon mesh membrane (40 $\mu \mathrm{m}$ mesh) to remove cell aggregates. Cells were then incubated with propidium iodide (final concentration $20 \mu \mathrm{g} / \mathrm{ml}$ in PBS, RNase A $(0.5 \mathrm{mg} / \mathrm{ml})$ and $0.1 \%$ Triton X100 overnight at $4^{\circ} \mathrm{C}$. Cells were analysed on a FACSCAN flow cytometer (Becton Dickinson, Mississauga, ON).

The release of nucleosomal DNA into the cytoplasm as a measure of apoptosis was determined using the Cell Death Detection ELISA kit according to the manufacturer's instructions (Roche, Laval, QC, Canada). Briefly, cells were lysed and the extracted cytoplasmic nucleosomal DNA was captured in ELISA wells containing anti-histone antibodies. The nucleosomal DNA was detected with an anti-DNA-POD conjugated antibody. The absorbance of each well was determined using a microplate reader at $410 \mathrm{~nm}$ (TecanSunrise, Research Triangle Pack, NC). Each sample was assayed in duplicate. Data are from three independent experiments.

The mitochondrial membrane integrity in OVCAR3 controls and knockdown cells was assayed using the MitoLight $^{\mathrm{TM}}$ Apoptosis Detection Kit (EMD Millipore). Cells were cultured in Labtek II chamber slides (Nalge Nunc International, Naperville, IL) in RPMI1640 supplemented with $20 \% \mathrm{FBS}$ at $37^{\circ} \mathrm{C}$ to achieve $70-80 \%$ confluence. Fresh media containing 200 ng/ml (OVCAR3 cells) or $500 \mathrm{ng} / \mathrm{ml}$ (SKOV3 cells) TRAIL was then added and cells were incubated at $37^{\circ} \mathrm{C}$ in $5 \% \mathrm{CO}_{2}$ for 45-60 min. After treatment with TRAIL, unfixed cells were incubated with the MitoLight ${ }^{\mathrm{TM}}$ reagent (Chemicon, Billerica, CA) (dilution 1:1,500) for $20 \mathrm{~min}$ at $37^{\circ} \mathrm{C}$. The wells were washed and identical fluorescein and rhodamine fields were digitized at 400× magnification using an Olympus X170 fluorescence microscope. Dye uptake by non-apoptotic mitochondria concentrates in the mitochondrial membrane and is visualized as the accumulation of red fluorescence in the organelles. However, apoptotic mitochondria are incapable of accumulating the dye due to loss of membrane potential and therefore the monomeric dye in the cytoplasm appears green.

\section{Immunoprecipitation and immunoblot analysis}

Whole cell extracts were prepared in lysing buffer containing protease inhibitors and were separated by $12 \%$ SDS-PAGE gels. Proteins were transferred to PVDF membranes (Roche, Laval, Québec, Canada) by electroblotting, and immunoblot analysis was performed as previously described (18). All primary antibodies were incubated overnight at $4{ }^{\circ} \mathrm{C}$ in $5 \%$ milk. Proteins were visualized by enhanced chemiluminescence (GE Healthcare, Baie d'Urfé, Québec, Canada). SKOV3 empty vector and SKOV3 MUC16CTD cell lines were lysed for an hour on ice and immunoprecipitates were obtained using anti-HIS, anti-myc-789 or isotypic anti-mouse IgG monoclonal antibodies conjugated to protein-G agarose (EMD Millipore, Billerica, CA). Immune complexes were separated by SDS-PAGE, immunoblotted and probed with anti-c-myc 9E10 antibodies and visualized by enhanced chemiluminescence. For TRAIL DISC analysis, $80 \%$ confluent cells were stimulated with $1 \mu \mathrm{g} / \mathrm{ml}$ (OVCAR3) or $2 \mu \mathrm{g} / \mathrm{ml}$ (SKOV3) of Flag-tagged TRAIL and $3 \mu \mathrm{g} / \mathrm{ml}$ of anti-Flag M2 (pre-incubated for $15 \mathrm{~min}$ ) in RPMI medium for 30 or $60 \mathrm{~min}$. Cells were then washed with ice-cold PBS and lysed with lysis buffer containing $30 \mathrm{mM}$ Tris- $\mathrm{Hcl}, 150 \mathrm{mM} \mathrm{NaCl}, 1 \%$ Triton supplemented with protease inhibitors. Lysates were cleared, normalized for protein concentration and the DISC were immunoprecipitated with protein $\mathrm{G}$ agarose beads overnight at $4^{\circ} \mathrm{C}$ on a rotating rod. For Western blot analysis, the beads were washed 4 times with lysis buffer and heated in lysis buffer $4 \times$ SDS before the supernatants were separated by $12 \%$ SDS-PAGE. NIH Image J software was used to quantify the intensity of each band on Western blots. In some experiments, cycloheximide $(200 \mu \mathrm{M})$ in DMSO was added for the indicated time.

\section{$R T-P C R$ analysis}

Total RNAs were extracted from Ctrl scFv- and MUC16 scFv-expressing OVCAR3 cells using Trizol (Life Technologies) according to the manufacturer's recommendations. RNA integrity was verified on gel by ethidium bromide staining and quantification was performed by determining absorbance at $260 \mathrm{~nm}$. For each sample, total RNA ( $2 \mu \mathrm{g}$ ) and $1 \mu \mathrm{M}$ of oligo dT (Promega) were incubated for $5 \mathrm{~min}$ at $70^{\circ} \mathrm{C}$ followed by the addition of 
90 units of the reverse transcriptase MMULV (Promega, Madison, WI) and $2.5 \mu \mathrm{M} d N T P$ for $1 \mathrm{~h}$ at $42^{\circ} \mathrm{C}$. Amplification of cDNA was done in a PCR reaction using the Taqman Gene Expression Assay Master mix from Applied Biosystems as follow: $2 \mathrm{~min}$ at $50^{\circ} \mathrm{C}, 10 \mathrm{~min}$ at $95^{\circ} \mathrm{C}$ and then 40 cycles of $15 \mathrm{~s}$ at $94^{\circ} \mathrm{C}$ and $1 \mathrm{~min}$ at $60^{\circ} \mathrm{C}$ on a StepOne Plus real time PCR system (Life Technologies Inc). The primers for the amplification of cFLIP $_{\mathrm{L}}$ (Gene expression assay Hs00153439_m1) and cFLIP $_{S}$ (Gene expression assay Hs00354474_m1) were from Life Technologies Inc.

\section{Flow cytometry for TRAIL receptors and MUC16 expression}

Cell monolayers were detached using EDTA, washed with PBS and fixed with paraformadehyde 4\% in PBS for $20 \mathrm{~min}$. Cells were incubated with the following unlabeled primary antibodies $(10 \mu \mathrm{g} / \mathrm{ml})$ for $1 \mathrm{~h}$ at room temperature with human anti-TRAIL-R1, -R2, -R3, and -R4 antibodies. The isotypic control antibody was a normal mouse IgG (BD Biosciences, Mississauga, ON). After three washes with PBS, cells were incubated with PE-conjugated donkey anti-mouse antibody (Jackson ImmunoResearch, West Grove, PA) for $45 \mathrm{~min}$ at room temperature. Cells were washed three times and analyzed immediately using a FACSCAN flow cytometer (Beckton Dickinson). After they had reached $80-90 \%$ confluence, MUC16 knockdown cells and ctrl scFv cells as well as the parental OVCAR3 cells were fixed with $4 \%$ paraformaldehyde. Cell surface MUC16 tumor antigen was detected by flow cytometry using the anti-CA125 M11 mouse monoclonal antibody and revealed using an anti-mouse PEconjugated (Jackson ImmunoResarch).

\section{Immunofluorescence}

Stable OVCAR3 clones expressing the various scFvs were grown on glass slides until a 50-70\% confluence was reached. Glass slides were then washed in cold PBS and cells fixed in ice-cold methanol for $10 \mathrm{~min}$ at $-20^{\circ} \mathrm{C}$. Glass slides were next rinsed $5 \mathrm{~min}$ in cold PBS, permeabilized in PBS containing 0.1\% Triton X-100 for 5 min on ice and rinsed again in PBS. Slides were blocked in $\mathrm{PBS} / 2 \% \mathrm{BSA}$ on ice for $45 \mathrm{~min}$ and incubated with primary antibodies in blocking buffer at room temperature for $1 \mathrm{~h}$. Slides were washed 3 times in cold PBS, incubated for $30 \mathrm{~min}$ at room temperature with anti-mouse secondary antibodies coupled to Texas Red (1:1000; Molecular Probes, Eugene, OR), washed with PBS and mounted for visualization by fluorescence microscopy. Expression of MUC16 was detected using M11 antibody (1:500). Nuclear staining performed with DAPI (100 $\mathrm{ng} / \mathrm{ml}$ ) (Roche), was viewed and photographed using an Olympus X170 fluorescence microscope.

\section{Statistical analysis}

Statistical comparisons between two groups were performed using the Student's $t$-test and with ANOVA when comparing the data with more than two treatments groups. Statistical significance was indicated by $P<0.05$.

\section{Results}

\section{MUC16 attenuates TRAIL-induced apoptosis and pro-} caspase- 8 activation

To determine whether MUC16 affects TRAIL signaling, we knockdown MUC16 cell surface expression. The cell surface localization of MUC16 was confirmed by co-localization with membrane protein Caveolin1 (Additional file 1: Figure S1). We thus derived antiMUC16 single-chain antibodies (scFvs), containing an ER retention signal, and a control scFv (Ctrl scFv), which does not bind to MUC16 [26,27]. These constructs were stably expressed in MUC16-expressing OVCAR3 cells and two independent MUC16 scFv-expressing cell lines were derived (1:9\#7 $\mathrm{scFv}$ and 1:9\#9 $\mathrm{scFv})$ as previously described [26,27]. As compared to the control scFv, expression of MUC16 scFvs strongly decreased MUC16 expression at the cell surface in OVCAR3 cells as demonstrated by both immunofluorescence and immunoblot (Figure 1). Treatment of control and MUC16 scFvexpressing OVCAR3 cells with increasing concentrations (0 to $100 \mathrm{ng} / \mathrm{ml}$ ) of TRAIL induced dose-dependent cell death (Figure 2A). However, MUC16 knockdown cells were significantly more sensitive to TRAIL-induced cell death. As shown in Figure 2B, following treatment with TRAIL (10 ng/ml), MUC16 knockdown cells were rounded and floated in the medium indicating cell death whereas the control scFv-expressing cells formed a typical healthy epithelioid monolayer. To further confirm that MUC16 knockdown enhances TRAIL-induced cell death, Ctrl scFv- and 1:9\#7 scFv-expressing OVCAR3 cells were incubated with an anti-TRAIL-R2 agonist antibody. As shown in Figure 2C, anti-TRAIL-R2 agonist-induced cell death was enhanced in MUC16 knockdown cells. Apoptosis, as measured by \% of hypodiploid cells assessed by flow cytometry, was similar for all cell populations in the absence of TRAIL (Figure 2D) suggesting that MUC16 knockdown by itself does not induce apoptosis. However, MUC16 knockdown significantly sensitized OVCAR3 cells to TRAIL-induced apoptosis $(P<0,001)$ (Figure $2 \mathrm{D})$. In concert with these findings, down-regulation of MUC16 increased TRAILinduced caspase- 8 activation as demonstrated by the near complete disappearance of pro-caspase- 8 and the appearance of p18 actives fragments after $3 \mathrm{~h}$ when compared to control scFv-expressing cells (Figure 2E). Analysis of TRAIL signaling cascade also indicated that cleaved mature forms of caspase-9 (p35) and caspase-3 


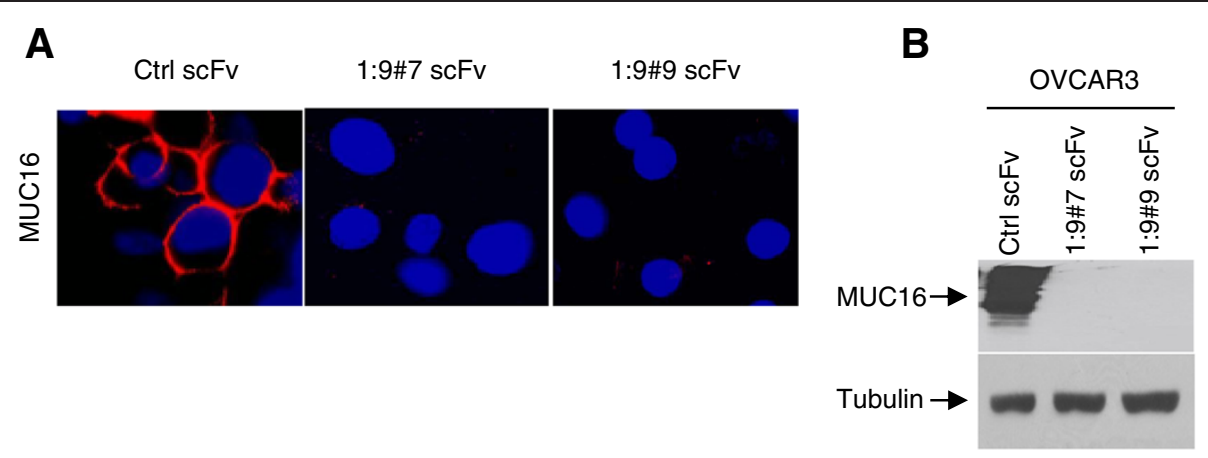

Figure 1 Cell surface knockdown of MUC16 in OVCAR3 sublines expressing ER-targeted anti-MUC16 scFvs. Ctrl scFv-expressing cell line and MUC16 knockdown (1:9\#7 SCFV and 1:9\#9 sCFv) cell were assessed for MUC16 expression by immufluorescence with anti-CA125 M11 antibody. (A) The expression of MUC16 in non-permeabilized cells was determined by immunofluorescence. Cells were incubated with the anti-CA125 M11 antibody and nuclei were stained with DAPI. (B) Immunoblot analysis of MUC16 expression. Equal loading was confirmed using an anti-tubulin antibody.

(p17) were generated in MUC16 knockdown cells within $1 \mathrm{~h}$. In contrast, control scFv-expressing cells displayed a more limited caspase- 9 and caspase- 3 activation over time in the presence of TRAIL under the same conditions. Caspase activation in control cells was seen only after 3 or $4 \mathrm{~h}$ and cleaved active caspase- 8 (p18) and caspase-3 (p17) were not observed even after $4 \mathrm{~h}$. The generation of active caspase-3 fragments in MUC16 knockdown OVCAR3 cells was confirmed by measuring the cleavage of fluorogenic caspase-3 substrates (Additional file 1: Figure S2A). Pre-incubation of cells with caspase-8 inhibitor z-IETD-fmk prior to TRAIL treatment $(25 \mathrm{ng} / \mathrm{ml})$ had little effect on TRAIL-induced apoptosis in the control scFv-expressing cells but significantly improved the survival of MUC16 knockdown cells (Additional file 1: Figure S2B).

Caspase-8 mediates the cleavage of full length Bid to generate a truncated form (tBid) which translocates to the mitochondria to promote the insertion of Bax into the outer membrane mitochondrial membrane [29,30]. tBid is therefore a key component that links the death receptor pathway to mitochondria-mediated effector caspase activation in type II cells. We thus assessed the impact of MUC16 knockdown on Bid cleavage in OVCAR3 cells. We observed the near complete disappearance of full length Bid within $3 \mathrm{~h}$ in MUC16 knockdown cells treated with TRAIL (Figure 2F). In contrast, the disappearance of Bid occurred only after $8 \mathrm{~h}$ in control scFv-expressing cells. The cleavage of Bid in MUC16 knockdown cells was almost completely inhibited by pre-incubation with caspase-8 inhibitor z-IETDfmk (Additional file 1: Figure S2C). To evaluate whether MUC16 also attenuates TRAIL-induced mitochondrial activation, mitochondria membrane integrity was assessed by the uptake of a lipophilic cationic dye. In the absence of TRAIL, there were little or no visible apoptotic mitochondria in both knockdown and control cells as indicated by the absence of green-labelled cells (Figure 2G). The red fluorescence represents dimeric dye that has accumulated in the intact mitochondria membrane. However, compared to control scFv-expressing cells, MUC16 knockdown cells treated with TRAIL displayed substantially more apoptotic mitochondria as shown by a greater number of green-labeled cells indicating the accumulation of dye in the cytoplasm due to the inability of mitochondria to concentrate the dye within their membranes related to a loss of membrane potential. All together, these results indicate that MUC16 attenuates TRAIL-induced apoptosis, activation of caspase- 8 and mitochondrial activation.

To further support the role of MUC16 in TRAIL resistance, we examined the expression of MUC16 in nine ovarian cancer cell lines. As shown in Table 1, with the exception of SKOV3 and OVC116 cell lines, the expression of MUC16 correlated with TRAIL sensitivity. More interestingly, MUC16 expression in TRAIL resistant OVCAR3 cells (OVCAR3 R350) was significantly higher than its isogenic sensitive parental cells (Figure 2G). The generation of the OVCAR3 R350 cell line has been previously described by our group [28].

\section{MUC16 C-terminal domain (CTD) is sufficient to attenuate TRAIL-induced apoptosis and signaling}

To determine whether the MUC16CTD is sufficient to attenuate TRAIL-induced apoptosis, the MUC16 negative SKOV3 cell line was transfected to stably express an empty vector (SKOV3-EV) or MUC16CTD as previously described [26,27]. MUC16CTD expression was detectable in SKOV3-MUC16CTD cells but not in control SKOV3-EV cells (Figure 3A). The appropriate cell surface localization of MUC16CTD in these cells has been validated previously [27]. Because we have previously shown that SKOV3 cells are less sensitive to TRAIL than OVCAR3 cells [7], higher doses of TRAIL were used for the treatment of SKOV3 cells. As shown in Figure 3B 


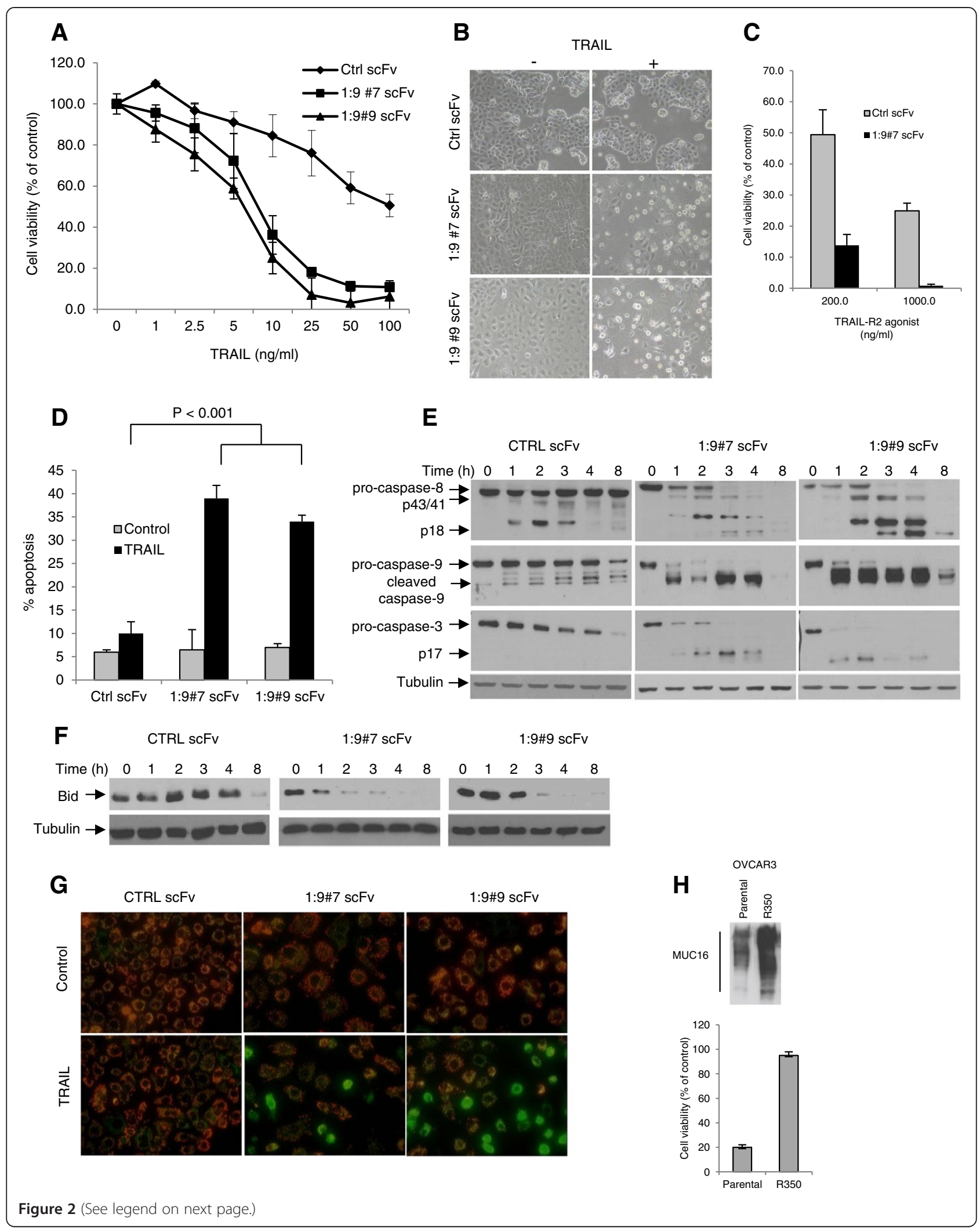


(See figure on previous page.)

Figure 2 MUC16 knockdown enhances TRAIL-induced activation of caspase-8 and apoptosis. (A) Cells were incubated for $48 \mathrm{~h}$ with increasing concentrations of TRAIL. Cell viability was measured by the XTT assay. All assays were performed in triplicate and repeated three times. Data are expressed as the mean of pooled data from all three experiments: bars, \pm SEM. (B) Cells were incubated in the presence or absence of TRAIL $(100 \mathrm{ng} / \mathrm{ml})$ for $24 \mathrm{~h}$, and morphological changes were assessed by phase contrast microscopy. Representative fields from one of two independent experiments are shown. (C) Cells were treated with anti-TRAlL-R2 agonist for $48 \mathrm{~h}$. Cell viability was measured by the XTT assay. All assays were performed in triplicate and repeated three times. Data are expressed as the mean of pooled data from all three experiments: bars, \pm SEM. (D) Cells were treated with TRAIL (100 ng/ml) for $24 \mathrm{~h}$ and stained with PI, and the subG0/G1 DNA content was analyzed by flow cytometry. Results from two independent experiments are shown. (E) Cells were treated with TRAlL (100 ng/ml) for up to $8 \mathrm{~h}$ and cell lysates were analyzed by immunoblots. (F) Cells were incubated with TRAlL for the indicated times and cell lysates were immunoblotted with anti-Bid antibody. The anti-Bid antibody used does not detect the truncated form of Bid. (G) Cells were cultured for $24 \mathrm{~h}$ without TRAIL and the mitochondrial membrane integrity was assessed using MitoLight ${ }^{\mathrm{TM}}$. In treated cells, fresh culture medium containing $200 \mathrm{ng} / \mathrm{ml}$ of TRAlL was added for 45 min prior to MitoLight ${ }^{T M}$ staining. Cells containing red-labeled mitochondria are scored as viable cells. (H) OVCAR3 and isogenic TRAIL resistant R350 cells were treated with TRAIL (100 ng/ml) for $48 \mathrm{~h}$ and cell viability was assessed by XTT. Immunoblot showing expression of MUC16 in the upper panel.

and C, TRAIL-induced cell death was significantly decreased in SKOV3 cells expressing MUC16CTD compared to empty vector (EV)-expressing cells $(P<0.001)$. TRAIL-induced apoptosis was decreased by about $50 \%$ in MUC16CTD-expressing SKOV3 cells compared to control SKOV3-EV cells (Figure 3D).

In SKOV3-EV cells, TRAIL induced the cleavage of pro-caspase- 8 into the active p43/41 after about $1 \mathrm{~h}$ (Figure 3E). Because these cells are less sensitive to TRAIL than OVCAR3 cells, the mature active p18 fragments were not detected in SKOV3-EV cells even after $6 \mathrm{~h}$. The cleavage of caspase- 3 and caspase- 9 was evident after $2 \mathrm{~h}$ as determined by the disappearance of pro-caspase form (Figure 3E). The expression of MUC16CTD markedly decreased the TRAIL-induced processing of caspase-8, caspase- 3 and caspase-9 in SKOV3 cells. There was no evidence of procaspase cleavage in these cells even after $6 \mathrm{~h}$ (Figure 3E). To determine whether TRAIL-induced activation of the mitochondrial pathway was attenuated by MUC16CTD, mitochondria membrane integrity was assessed by the uptake of a lipophilic cationic dye. Experiments showed that MUC16CTD strongly decreased the number of apoptotic mitochondria (Figure 3D). All together, these findings indicate that MUC16CTD is sufficient to inhibit TRAILinduced caspases activation and apoptosis.

Table 1 MUC16 expression and TRAIL sensitivity

\begin{tabular}{lll}
\hline $\begin{array}{l}\text { Ovarian cancer } \\
\text { cell lines }\end{array}$ & $\begin{array}{l}\text { Relative MUC16 surface } \\
\text { expression (MFI) }\end{array}$ & TRAIL IC50 (ng/ml) \\
\hline OVCAR3 & 527 & 10 \\
OVCAR3 R350 & 1250 & $>500$ \\
SKOV3 & $<10$ & $>500$ \\
CaOV3 & 49,6 & 20 \\
OVC116 & $<10$ & 25 \\
OVC118 & 325 & 125 \\
COV2 & 628 & $>500$ \\
COV17 & 842 & $>500$ \\
\hline
\end{tabular}

MUC16 decreases TRAIL-R2 expression and its recruitment at the DISC

Differential sensitivity to TRAIL-induced apoptosis in tumor cells has been previously attributed to differential expression of death and decoy receptors [30]. Indeed, the levels of TRAIL receptors (TRAIL-R1 and -R2) are closely related to apoptosis induced by TRAIL. It is therefore possible that MUC16 regulates the TRAIL signaling cascade by altering the expression of TRAIL receptors. In this context, we examined the cell surface expression of the four TRAIL receptors by flow cytometry in control and MUC16 knockdown cells. TRAIL-R2 expression was significantly increased in MUC16 knockdown OVCAR3 cells whereas the expression of the other TRAIL receptors remained unchanged (Figure 4A). In concert with these results, the assessment of TRAIL-R2 by immunoblot showed increased expression of TRAILR2 in MUC16 knockdown cells (Figure 4B). In contrast, the expression of MUC16CTD was sufficient to decrease TRAIL-R2 expression in SKOV3 cells (Figure 4C).

Binding of TRAIL to TRAIL-R1/TRAIL-R2 results in recruitment of FADD to the DISC and, in turn, FADD recruits pro-caspase-8 [8]. Because MUC16 decreases TRAIL-R2 expression, we determine whether MUC16 affects DISC formation. The composition of TRAIL DISC was analyzed by immunoprecipitation and immunoblotting using cross-linked recombinant Flagtagged soluble TRAIL. In MUC16 knockdown OVCAR3 cells, pro-caspase- 8 activation at the DISC, as demonstrated by the presence of p43/41 fragments, was clearly enhanced when compared to the control scFv-expressing cells (Figure 4D). Immunoblot analysis further revealed increased TRAIL-R2 recruitment at the DISC in MUC16 knockdown cells (Figure 4D) which is consistent with the increased expression of TRAIL-R2 in these cells (Figure 4A and B). In line with experiments in OVCAR3 cells and those shown in Figure 4C, fewer TRAIL-R2 receptors were pulled down by immunoprecipitating flag-tagged TRAIL from SKOV3 MUC16CTD cells and 


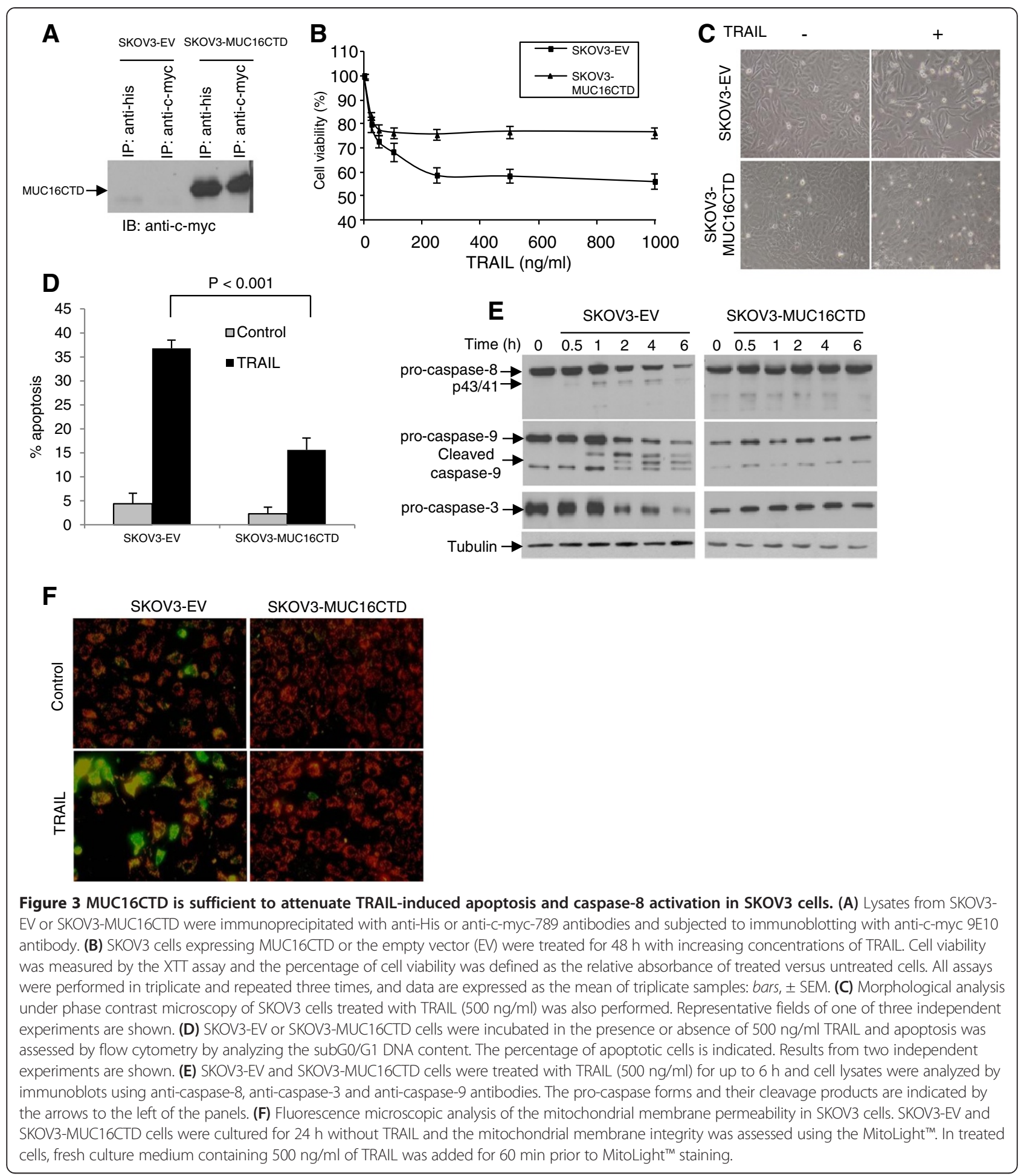

cleaved caspase- 8 fragments ( $\mathrm{p} 43 / 41$ ) were detected only in the DISC of control SKOV3-EV cells after $60 \mathrm{~min}$ (Figure 4E). These data suggest that MUC16 attenuates TRAIL-induced apoptosis by decreasing TRAIL-R2 expression and consequently decreasing its recruitment at the DISC.

\section{MUC16 regulates cFLIP expression}

The cellular FLICE inhibitory protein (cFLIP) regulates both recruitment and processing of pro-caspase- 8 within the DISC $[13,14]$. Although several cFLIP isoforms have been described, the two main isoforms expressed in human cells are $\operatorname{cFLIP}_{\mathrm{L}}(55 \mathrm{kDa})$ and $\operatorname{cFLIP}_{\mathrm{s}}(25 \mathrm{kDa})$ 

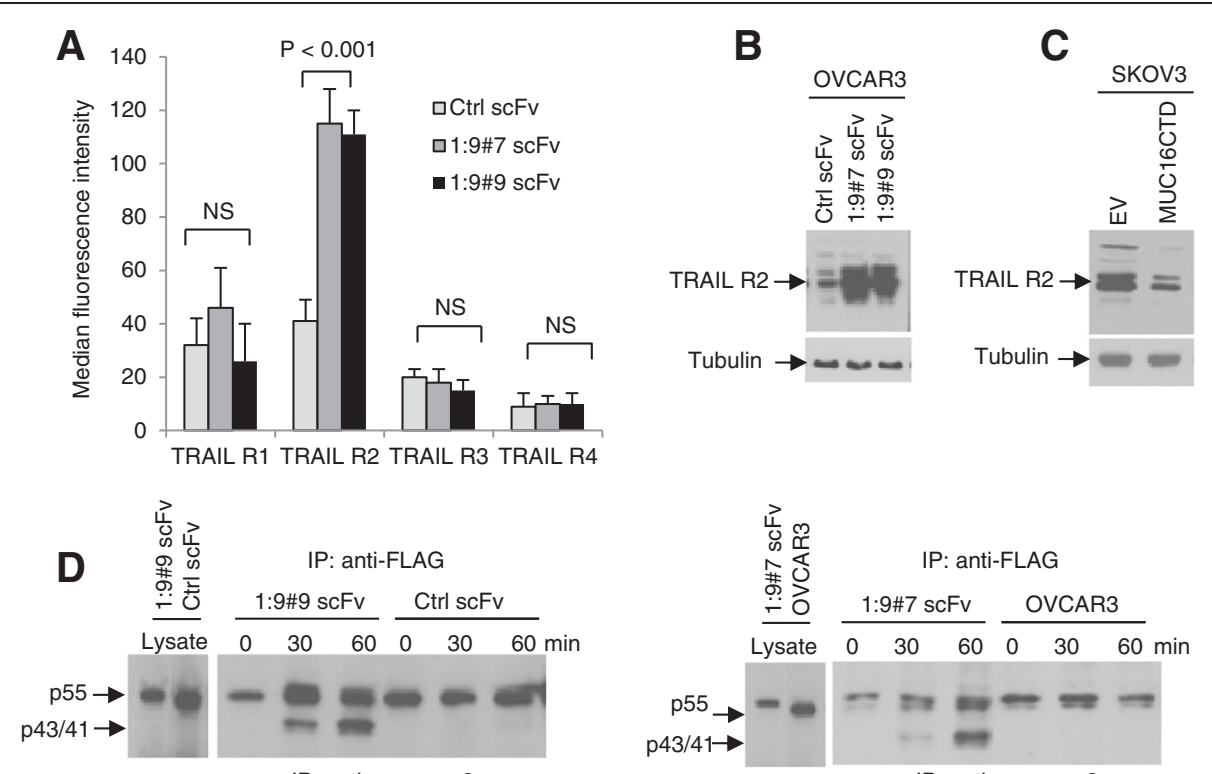

IB: anti-caspase-8

IB: anti-caspase-8
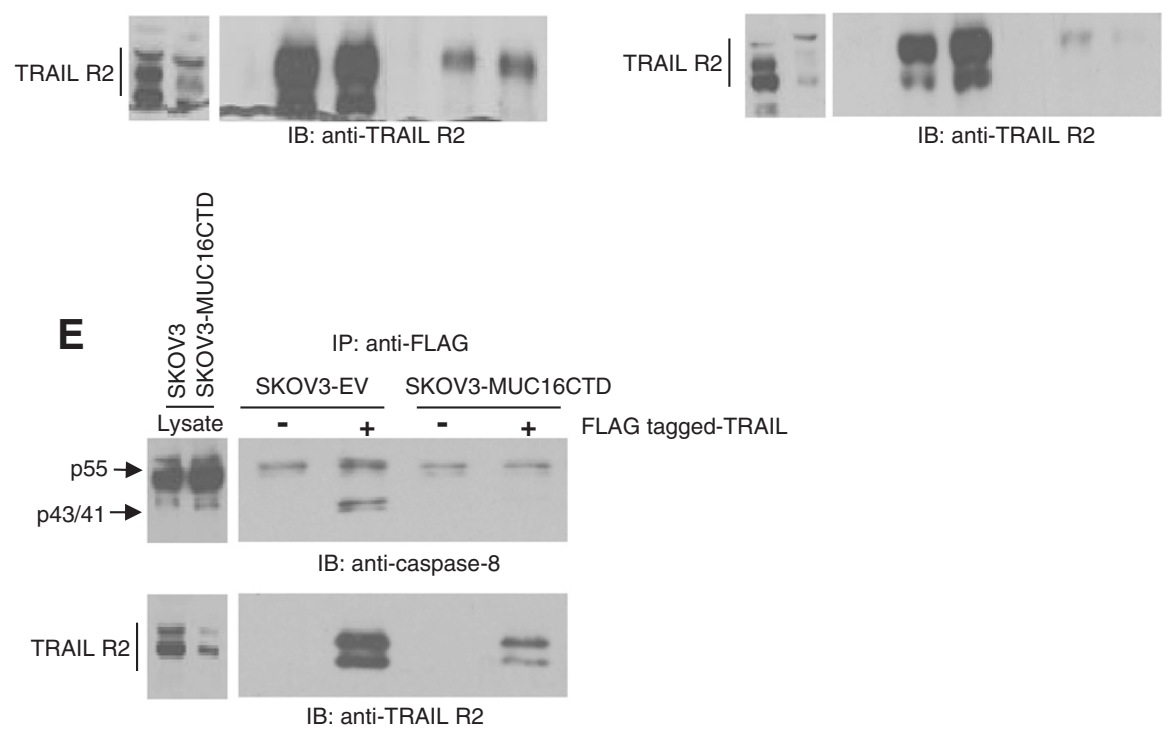

Figure 4 MUC16 decreases TRAIL-R2 expression and blocks caspase-8 activation at the DISC. (A) Monolayers of Ctrl sCFV- and MUC16 scFv-expressing cells were detached using EDTA, washed with PBS and fixed with paraformadehyde 4\% in PBS. Cells (non-permeabilized) were incubated with anti-TRAIL receptors R1, R2, R3 and R4 antibodies. Expression of TRAIL receptors was determined by flow cytometry and expressed as median fluorescence units. Results are from three independent experiments. (B) Lysates from Ctrl scFv- and MUC16 scFv-expressing OVCAR3 cells were immunoblotted with TRAIL-R2 antibody. (C) Lysates from empty vector (EV)- and MUC16CTD-expressing SKOV3 cells were immunoblotted with TRAlL-R2 antibody. (D) Ctrl scFv- and MUC16 scFv-expressing OVCAR3 cells were incubated with FLAG-tagged TRAlL (1 $\mu \mathrm{g} / \mathrm{ml})$ for various times and the DISC was immunoprecipitated with anti-FLAG antibody. The membrane was immunoblotted with anti-caspase-8 antibody or with anti-TRAIL R2. Data are representative of at least two independent experiments. (E) Empty vector (EV)- and MUC16CTD-expressing SKOV3 cells were incubated with FLAG-tagged TRAIL $(2 \mu \mathrm{g} / \mathrm{ml})$ and the DISC was immunoprecipitated with anti-FLAG antibody. The membrane was immunoblotted with anti-caspase-8 antibody or with anti-TRAIL R2. Data are representative of at least two independent experiments.

$[13,14]$. Because both cFLIP $_{\mathrm{L}}$ and $\mathrm{cFLIP}$ S are key regulators of the TRAIL signaling cascade, we first assessed whether MUC16 affects the transcription of $\mathrm{CFLIP}_{\mathrm{L}}$ and cFLIP $_{\mathrm{S}}$. We thus examined cFLIP $_{\mathrm{L}}$ and cFLIP $_{\mathrm{S}}$ mRNA levels in control and MUC16 scFv-expressing OVCAR3 cells. cFLIP $\mathrm{L}_{\mathrm{L}}$ and $\mathrm{cFLIP}$ S mRNA levels, as determined by quantitative real time PCR, were significantly decreased in MUC16 knockdown OVCAR3 cells compared to control scFv expressing cells (Figure 5A). In concert with these findings, the expression of both FLLIP $_{\mathrm{L}}$ and $\mathrm{CFLIP}_{\mathrm{S}}$ were decreased in MUC16 knockdown cells when assessed by immunoblot (Figure $5 \mathrm{~B}$ ). To determine if MUC16 affects cFLIP ${ }_{\mathrm{L}}$ stability, we blocked de novo protein synthesis with cycloheximide and assessed $\mathrm{cFLIP}_{\mathrm{L}}$ 


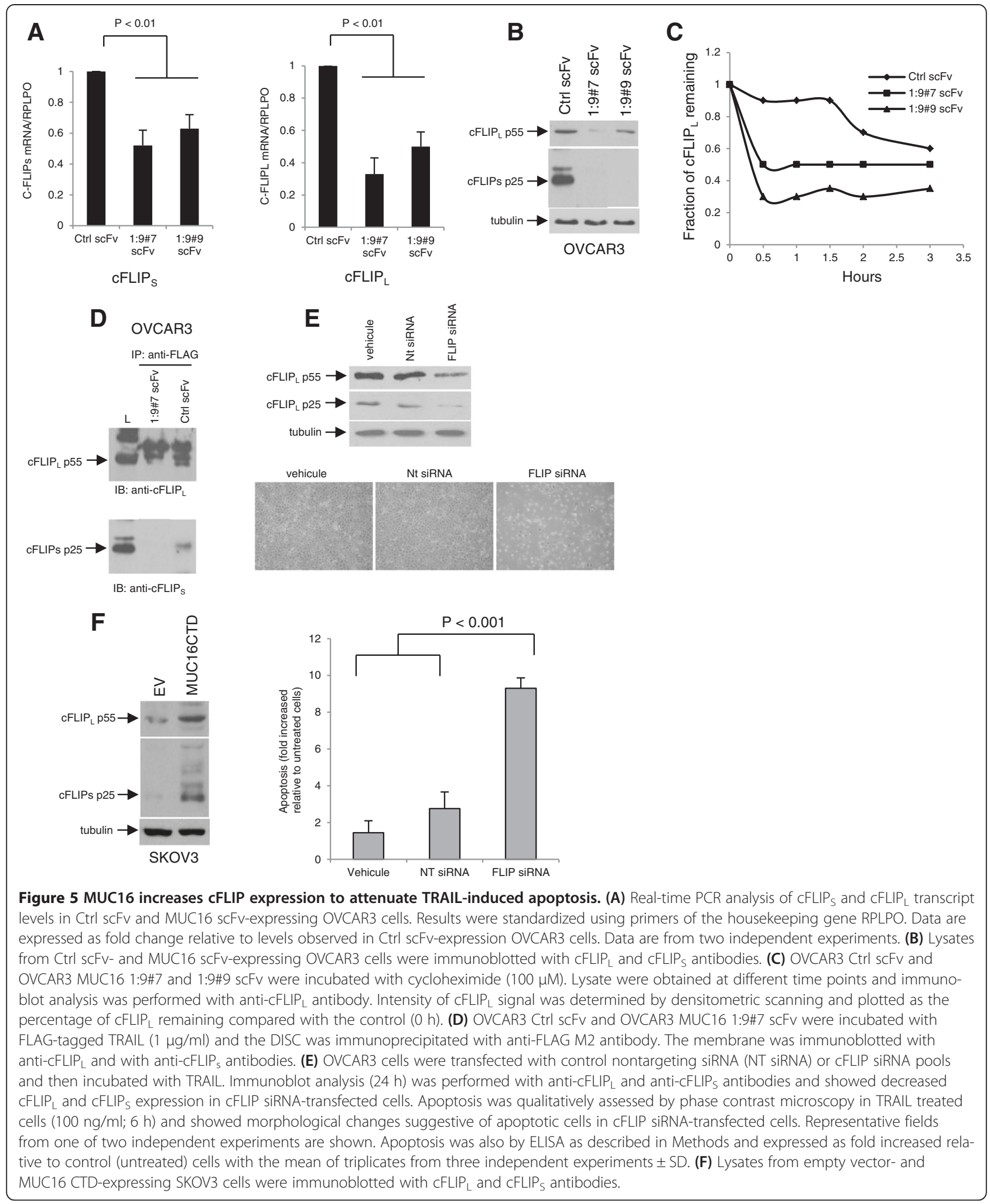

and $\mathrm{cFLIP}_{\mathrm{S}}$ expression at different times after the addition of cycloheximide. Densitometric scanning of the signals showed that the estimated half-lives of
cFLIP $_{\mathrm{L}}$ in control scFv- and MUC16 scFv-expressing OVCAR3 cells are $>3$ and $\leq 0.5$ hours, respectively (Figure $5 \mathrm{C}$ ). The half-live of $\mathrm{cFLIP}_{\mathrm{S}}$ was estimated to 
be $\leq 0.5$ hours in control scFv-expressing OVCAR3 cells (data not shown). Because of the very low expression of cFLIP $_{S}$ in MUC16 knockdown cells, its half-live could not be determined using this approach. Nonetheless, these data indicate that MUC16 stabilizes $\mathrm{CFLIP}_{\mathrm{L}}$ which might contribute to attenuate TRAIL-induced apoptosis in MUC16 expressing malignant cells. Indeed, $\mathrm{CFLIP}_{\mathrm{L}}$ and CFLIP $_{S}$ recruitment at the DISC were both decreased in MUC16 knockdown cells as compared to control scFv-expressing cells (Figure 5D). In addition, silencing cFLIP in OVCAR3 cells was associated with increased apoptosis in response to TRAIL (Figure 5E). Consistent with these findings, the expression of MUC 16CTD in SKOV3 cells was associated with the upregulation of $\mathrm{CFLIP}_{\mathrm{L}}$ and $\mathrm{CFLIP}_{\mathrm{S}}$ as demonstrated by immunoblot (Figure 5F). Of note, the expression of other key regulators of the TRAIL signaling cascade such as Bcl-2, Bcl-XL, Bax, FADD and XIAP were unaffected by MUC16 (Additional file 1: Figures S2D and S2E). These data indicate that MUC16 transcriptionally increases both isoforms of cFLIP and at least $\mathrm{CFLIP}_{\mathrm{L}}$ protein, thereby increasing their recruitment at the DISC to attenuate TRAIL-induced apoptosis.

\section{Discussion}

MUC16 is a mucin protein overexpressed by most human ovarian epithelial cancers [19,31,32]. Moreover, a correlation exists between rising and falling levels of serum MUC16 and clinical progression and regression of the disease [31]. In this context, it is considered to be one of the most useful clinical markers for ovarian cancer. Although its biological functions remain largely unknown, MUC16 expression in EOC cells has been associated with a more aggressive phenotype [26]. In addition, our group has recently implicated MUC16 in the regulation of genotoxic drug-induced apoptosis but the mechanisms associated with the effect were unclear [27]. In the present study, we demonstrate that MUC16 is involved in the regulation the death receptor pathway. Cell surface MUC16 knockdown, mediated by antiMUC16 scFvs, sensitizes ovarian cancer cell line OVCA R3 to apoptosis in response to TRAIL, a member of the TNF family of cytokines that represents a promising candidate for cancer treatment because of its ability to selectively induce apoptosis in malignant cells [5]. TRAIL-induced activation of initiator caspase- 8 and effector caspase- 3 was enhanced in MUC16 knockdown cells. MUC16 knockdown was associated with increased TRAIL-R2 expression and recruitment at the DISC. MUC16 knockdown also decreases the expression of the caspase-8 inhibitor cFLIP at the transcriptional level and enhanced the protein degradation of $\mathrm{cFLIP}_{\mathrm{L}}$ isoform, thereby enhancing apoptosis in response to TRAIL. Conversely, MUC16CTD expression attenuated TRAIL- induced apoptosis and caspase activation by decreasing TRAIL-R2 expression and recruitment at the DISC and by increasing cFLIP expression. These data suggest that MUC16 plays an important role in regulating the death receptor signaling cascade.

Mucins play a role in carcinogenesis by promoting anchorage-independent growth and tumorigenicity of human epithelial cells. Altered expression of mucins has been associated with increased invasiveness, enhanced tumor cell growth and metastasis, and modulation of cell adhesion in carcinomas [32-38]. Based on its similarity of structure with mucins, it is conceivable that MUC16 exerts a number of functions that parallel those of other mucins. Interestingly, it has been reported that MUC1 can block death receptor-mediated apoptosis in breast and colonic carcinoma cells [39,40]. This effect has been attributed to localization of MUC1 C-terminal domain to the mitochondria which attenuated mitochondrial activation [40] or to the ability of MUC1 to directly bind caspase- 8 and FADD, thereby inhibiting recruitment of caspase- 8 at the DISC [39]. Thus, similar to MUC1, MUC16 attenuates TRAIL-induced apoptosis in EOC cells and both mucins may act upstream of the mitochondria. However, the mechanisms by which they inhibit TRAIL signaling differ. MUC16 acts through multiple mechanisms to attenuate TRAIL-induced apoptosis. MUC16 down-regulates TRAIL-R2 and up-regulates cFLIP expression both resulting in the inhibition of caspase- 8 activation at the DISC. The basis for this discrepancy in term of mechanisms between MUC1 and MUC16 is unclear but may relate to the fact that different cellular models were used or, more likely, to the fact that MUC1 and MUC16 share very little sequence homology in their cytoplasmic tail [41]. MUC16 has a very short intracellular domain (31 a.a.) compared to MUC1 (72 a.a.). Nonetheless, collectively the data suggest that transmembrane mucins, such as MUC1 and MUC16, regulate the extrinsic pathway of apoptosis. By doing so, mucins may enable tumor cells to escape the cytotoxic effect of immune cells and promote tumor development.

Our study provides important insight into the molecular mechanisms by which MUC16 regulates TRAILmediated apoptosis. TRAIL binds to distinct receptors but among these receptors, only TRAIL-R1 and TRAILR2 contain cytoplasmic death domains that can transduce an apoptotic signal upon TRAIL binding. Our studies show that although both TRAIL-R1 and TRAILR2 are expressed at the surface of OVCAR3 and SKOV3 cell populations, TRAIL-R2 appears to be the main receptors used by TRAIL to transduce a death signal in these cells. This is supported by the observation MUC16 knockdown enhances anti-TRAIL-R2 agonist-mediated apoptosis. Although the precise mechanism by which MUC16 alters TRAIL-R2 expression selectively remains 
to be elucidated, MUC16 expression was associated with a lower expression of TRAIL-R2. Lack or low expression of TRAIL-R2 has been previously associated with TRAIL resistance [30]. Reduced TRAIL-R2 expression on the cell surface may result from either a lower level of expression in the cell or failure to deliver the receptor to the cell surface. Western blotting showed that the total protein levels of TRAIL-R2 are significantly lower in MUC16 expressing cells. This observation does not suggest a defective transport or a trafficking problem as we would expect identical levels of TRAIL-R2 in MUC16expressing and control cells. A more likely explanation would be a regulation of TRAIL-R2 at the transcriptional levels or increased protein degradation. Microarray analysis to investigate the global changes in MUC16 knockdown OVCAR3 cells revealed a significant (2.71) up-regulation of TRAIL-R2 gene but not TRAIL-R1 (unpublished data). We are currently investigating the mechanisms by which MUC16 regulates TRAIL-R2 expression. Markedly increased pro-caspase8 cleavage was seen within the DISC of MUC16 knockdown OVCAR3 cells while pro-caspase-8 activation into the DISC was not detected in the SKOV3 ectopically expressing MUC16CTD. Furthermore, OVCAR3 cells endogenously expressing high levels of MUC16 displayed very little pro-caspase- 8 processing after incubation with TRAIL for $1 \mathrm{~h}$ (Figure 4D). After initial cleavage of procaspase- 8 at the DISC, active caspase- 8 may directly activate effector caspases such as caspase-3 or may alternatively activate the cleavage and translocation of the pro-apoptotic protein Bid to the mitochondria [42]. The activation of the mitochondrial apoptotic pathway leads to cytochrome c release, caspase- 9 and caspase- 3 activation [42]. Kinetic analysis of caspase- 9 and caspase- 3 activation in OVCAR3 showed that the mitochondrial pathway is activated regardless of the cell's MUC16 status. However the activation of this pathway is markedly enhanced in MUC16 knockdown cells (Figure 3E). Interestingly, addition of a caspase- 9 inhibitor abrogated this effect indicating that mitochondrial amplification of TRAIL death signaling is important in MUC16 knockdown cells (data not shown). Based on our results, we propose that MUC16 interferes with the caspase- 8 activation at the DISC and consequently affects initiation of the mitochondrial amplification loop that leads to TRAIL-induced apoptosis.

It was recently shown that MUC16 silencing in breast cancer cells is associated with up-regulation of TRAILR1 (DR4) and pro-apoptotic molecules Bid and Bax, and down-regulation of $\mathrm{Bcl}-2$ [43]. The authors speculated that these changes might promote TRAIL-induced apoptosis in breast cancer cells but the level of the blockade in the death receptor signaling cascade was not established. In EOC cells, neither the expression of
MUC16CTD nor MUC16 knockdown was associated with altered expression of Bid, Bax, Bcl-2 or TRAIL-R1, and the blockade occurred upstream of the mitochondria. The basis for the discrepancy between these results is not clear. The role of anti-apoptotic proteins such as $\mathrm{Bcl}-2$ and $\mathrm{Bcl}-\mathrm{XL}$ in protecting from drug-induced apoptosis has been shown to be cell context dependent [44].

\section{Conclusions}

In summary, our results indicated that MUC16 attenuates TRAIL-induced apoptosis in EOC cells. Further, MUC16 down-regulates TRAIL R2 expression and recruitment at the DISC. MUC16 also increase the expression of both $\mathrm{cFLIP}_{\mathrm{L}}$ and $\mathrm{cFLIP}_{\mathrm{S}}$. Altogether, these effects contribute to the MUC16-mediated attenuation of TRAIL-induced apoptosis. The present findings may also have therapeutic implications. In this context, a combination of TRAIL with small molecules that block cell surface localization or the function of the intracellular domain of MUC16 might prove more effective in killing TRAIL resistant ovarian cancer cells. A clearer understanding of the mechanisms underlying MUC16 intracellular signaling could lead to the development of novel approaches to enhance the efficacy of TRAIL for the treatment of ovarian cancer.

\section{Additional file}

\begin{abstract}
Additional file 1: Figure S1. Expression and localization of MUC16 in OVCAR3 cells. Immunofluorescence studies were performed as described in Methods. MUC16 and caveolin1 were visualized with Texas Red (MUC16) or Alexa fluorescent label (green; caveolin1). Representative images are shown. Scale $=100 \mu \mathrm{M}$. Data demonstrate that MUC16 co-localization at the cell membrane with caveolin1. Figure S2. MUC16 enhanced TRAlL-induced Bid cleavage and mitochondrial activation. (a) The parental OVCAR3 cell line and sublines (ctrl scFv, 1:9\#7 scFv and 1:9\#9 scFv) were treated with TRAIL (100 ng/ml) and caspase-3 activity was measured using a caspase-3 fluorogenic protease assay. In brief, after TRAIL treatment, cells were lysed in $250 \mu \mathrm{l}$ of lysis buffer and lysates were incubated with $50 \mu \mathrm{M}$ of DEVD-AFC substrate for $1 \mathrm{~h}$. Caspase-3 activity was measured using the Versa Fluor fluorometer (b) Parental NIH:OVCAR3 cells and sublines (ctrl scFv, 1.9\#7 and 1.9\#9) were treated with TRAIL (100 ng/ml) for $6 \mathrm{~h}$. The activity of caspase-3 was measured using a caspase-3 fluorogenic protease assay with $50 \mu \mathrm{M}$ of DEVD-AFC as a substrate. Results are expressed as relative fluorescence unit (RFU) of caspase-3 activity normalized for the total amount of protein in the extract and represent mean \pm SEM $(n=3)$. ${ }^{*}$, indicates $P<0.001$.
\end{abstract}

\section{Competing interests}

The authors report no declarations of interest.

\section{Authors' contributions}

IM participated in the design of the study and performed most of the experiments. DL performed the TRAIL sensitivity assays and some of the assays for measuring apoptosis. MB generated and validated the MUC6CTD-expressing SKOV3 cells. CR participated in the design of the study and helped to draft the manuscript. AP conceived the study, participated in its design and drafted the manuscript. All authors read and approved the final manuscript

\section{Acknowledgements}

This work was supported by an internal grant from Université de Sherbrooke (A.P. and C.R.) and by the National Cancer Institute with funds from the Canadian Cancer Society to C.R. (\#011225 and \#014263). 
Received: 23 October 2013 Accepted: 24 March 2014

Published: 1 April 2014

\section{References}

1. Goncharenko-Khaider N, Lane D, Matte I, Rancourt C, Piché A: Targeted ovarian cancer treatment: the TRAILs of resistance. Am J Cancer Res 2012, 2:75-92.

2. Ashkenazi A, Dixit VM: Death receptors: signaling and modulation. Science 1998, 281:1305-1308.

3. Ashkenazi A, Holland P, Eckhardt SG: Ligand-based targeting of apoptosis in cancer: the potential of recombinant human apoptosis ligand 2/Tumor necrosis factor-related apoptosis-inducing ligand (rhApo2L/TRAIL). J Clin Oncol 2008, 26:3621-3630.

4. Walczak H, Miller RE, Ariail K, Gliniak B, Griffith TS, Kubin M, Chin W, Jones J, Woodward A, Le T, Smith C, Smolak P, Goodwin RG, Rauch CT, Schuh JC, Lynch DH: Tumoricidal activity of tumor necrosis factor-related apoptosis-inducing ligand in vivo. Nat Med 1999, 5:157-163.

5. Ozören N, El-Deiry WS: Cell surface death receptor signaling in normal and cancer cells. Semin Cancer Biol 2003, 13:135-147.

6. Wajant H, Pfizenmaier K, Scheurich P: TNF-related apoptosis inducing ligand (TRAIL) and its receptors in tumor surveillance and cancer therapy. Apoptosis 2002, 7:449-459.

7. Lane D, Cartier A, L'Espérance S, Côté M, Rancourt C, Piché A: Differential induction of apoptosis by tumor necrosis factor-related apoptosisinducing ligand in human ovarian carcinoma cells. Gynecol Oncol 2004, 93:594-604.

8. Kischkel FC, Lawrence DA, Chuntharapai A, Schow P, Kim KJ, Ashkenazi A: Apo2L/TRAIL-dependent recruitment of endogenous FADD and caspase-8 to death receptors 4 and 5. Immunity 2000, 12:611-620.

9. Degli-Esposti MA, Smolak PJ, Walczak H, Waugh J, Huang CP, DuBose RF, Goodwin RG, Smith CA: Cloning and characterization of TRAIL-R3, a novel member of the emerging TRAIL receptor family. J Exp Med 1997, 186:1165-1170.

10. Degli-Esposti MA, Dougall WC, Smolak PJ, Waugh JY, Smith CA, Goodwin RG: The novel receptor TRAIL-R4 induces NF-kappaB and protects against TRAIL-mediated apoptosis, yet retains an incomplete death domain. Immunity 1997, 7:813-820.

11. Emery JG, McDonnell P, Burke MB, Deen KC, Lyn S, Silverman C, Dul E, Appelbaum ER, Eichman C, DiPrinzio R, Dodds RA, James IE, Rosenberg M, Lee JC, Young PR: Osteoprotegerin is a receptor for the cytotoxic ligand TRAIL. J Biol Chem 1998, 273:14363-14367.

12. Kischkel FC, Hellbardt S, Berhmann I, Germer M, Pawlita M, Krammer PH, Peter ME: Cytotoxicity-dependent APO-1 (Fas/CD95)-associated proteins form a death-inducing signaling complex (DISC) with the receptor. EMBO J 1995, 14:5579-5588.

13. Krueger A, Baumann S, Krammer PH, Kirchhoff S: FLICE-inhibitory proteins: regulators of death receptor-mediated apoptosis. Mol Cell Biol 2001, 21:8247-8254.

14. Bagnoli M, Canevari S, Mezzanzanica D: Cellular FLICE-inhibitory protein (c-FLIP) signalling: a key regulator of receptor-mediated apoptosis in physiologic context and in cancer. Int I Biochem Cell Biol 2010, 42:210-213.

15. O'Brien TJ, Beard JB, Underwood LJ, Dennis RA, Santin AD, York L: The CA 125 gene: an extracellular superstructure dominated by repeat sequences. Tumour Biol 2001, 22:348-366.

16. O'Brien TJ, Beard JB, Underwood LJ, Shigemasa K: The CA 125 gene: a newly discovered extension of the glycosylated $\mathrm{N}$-terminal domain doubles the size of this extracellular superstructure. Tumour Biol 2002, 23:154-169.

17. Yin BW, Lloyd KO: Molecular cloning of the CA125 ovarian cancer antigen: identification as a new mucin, MUC16. J Biol Chem 2001, 276:27371-27375

18. Yin BW, Dnistrian A, Lloyd KO: Ovarian cancer antigen CA125 is encoded by the MUC16 mucin gene. Int J Cancer 2002, 98:737-740.

19. Kabawat SE, Bast RC, Welch WR, Knapp RC, Colvin RB: Immunopathologic characterization of a monoclonal antibody that recognizes common surface antigens of human ovarian tumors of serous, endometrioid, and clear cell types. Am J Clin Pathol 1983, 79:98-104.

20. Gubbels JA, Belisle J, Onda M, Rancourt C, Migneault M, Ho M, Bera TK, Connor J, Sathyanarayana BK, Lee B, Pastan I, Patankar MS: MesothelinMUC16 binding is a high affinity, N-glycan dependent interaction that facilitates peritoneal metastasis of ovarian tumors. Mol Cancer 2006, 5:50.
21. Kaneko O, Gong L, Zhang J, Hansen JK, Hassan R, Lee B, Ho M: A binding domain on mesothelin for CA125/MUC16. J Biol Chem 2009, 284:3739-3749.

22. Rump A, Morikawa Y, Tanaka M, Minami S, Umesaki N, Takeuchi M, Miyajima A: Binding of ovarian cancer antigen CA125/MUC16 to mesothelin mediates cell adhesion. J Biol Chem 2004, 279:9190-9198.

23. Argüeso P, Guzman-Aranguez A, Mantelli F, Cao Z, Ricciuto J, Panjwani N: Association of cell surface mucins with galectin-3 contributes to the ocular surface epithelial barrier. J Biol Chem 2009, 284:23037-23045.

24. Belisle JA, Horibata $S$, Jennifer GA, Petrie S, Kapur A, André S, Gabius HJ, Rancourt C, Connor J, Paulson JC, Patankar MS: Identification of Siglec-9 as the receptor for MUC16 on human NK cells, B cells, and monocytes. Mol Cancer 2010, 9:118.

25. Gubbels JA, Felder M, Horibata S, Belisle JA, Kapur A, Holden H, Petrie S, Migneault M, Rancourt C, Connor JP, Patankar MS: MUC16 provides immune protection by inhibiting synapse formation between NK cells and ovarian tumor cells. Mol Cancer 2010, 9:11.

26. Thériault $\mathrm{C}$, Pinard $\mathrm{M}$, Comamala M, Migneault M, Beaudin J, Matte I, Boivin M, Piché A, Rancourt C: MUC16 (CA125) regulates epithelial ovarian cancer cell growth, tumorigenesis and metastasis. Gynecol Oncol 2011, 121:434-443.

27. Boivin M, Lane D, Piché A, Rancourt C: CA125 (MUC16) tumor antigen selectively modulates the sensitivity of ovarian cancer cells to genotoxic drug-induced apoptosis. Gynecol Oncol 2009, 115:407-413.

28. Lane D, Côté M, Grondin M, Couture MC, Piché A: Acquired resistance to TRAIL-induced apoptosis in human ovarian cancer cells is conferred by increased turnover of mature caspase-3. Mol Cancer Ther 2006, 5:509-521.

29. Ott M, Norberg E, Zhivotovsky B, Orrenius S: Mitochondrial targeting of tBid/ Bax: a role for the TOM complex? Cell Death Differ 2009, 16:1075-1082.

30. Kim K, Fisher MJ, Xu SQ, El-Deiry WS: Molecular determinants of response to TRAIL in killing of normal and cancer cells. Clin Cancer Res 2000, 6:335-346.

31. Bast RC Jr, Klug TL, St John E, Jenison E, Niloff JM, Lazarus H, Berkowitz RS, Leavitt T, Griffiths CT, Parker L, Zurawski VR Jr, Knapp RC: A radioimmunoassay using a monoclonal antibody to monitor the course of epithelial ovarian cancer. N Engl J Med 1983, 309:883-887.

32. Hogdall EV, Christensen L, Kjaer SK, Blaakaer J, Kjaerbye-Thygesen A, Gayther S, Jacobs IJ, Hogdall CK: CA125 expression pattern, prognosis and correlation with serum CA125 in ovarian tumor patients. From the Danish "MALOVA" ovarian cancer study. Gynecol Oncol 2007, 104:508-515.

33. Hilkens J, Ligtenberg MJ, Vos HL, Litvinov SV: Cell membrane-associated mucins and their adhesion-modulating property. Trends Biochem Sci 1992, 17:359-363.

34. Wesseling J, van der Valk SW, Vos HL, Sonnenberg A, Hilkens J: Episialin (MUC1) overexpression inhibits integrin-mediated cell adhesion to extracellular matrix components. J Cell Biol 1995, 129:255-265.

35. Komatsu M, Jepson S, Arango ME, Carothers Carraway CA, Carraway KL: Muc4/sialomucin complex, an intramembrane modulator of ErbB2/HER2/ $\mathrm{Neu}$, potentiates primary tumor growth and suppresses apoptosis in a xenotransplanted tumor. Oncogene 2001, 20:461-470.

36. Satoh S, Hinoda Y, Hayashi T, Burdick MD, Imai K, Hollingsworth MA: Enhancement of metastatic properties of pancreatic cancer cells by MUC1 gene encoding an anti-adhesion molecule. Int I Cancer 2000, 88:507-518,

37. Singh AP, Moniaux N, Chauhan SC, Meza JL, Batra SK: Inhibition of MUC4 expression suppresses pancreatic tumor cell growth and metastasis. Cancer Res 2004, 64:622-630.

38. McDermott KM, Crocker PR, Harris A, Burdick MD, Hinoda Y, Hayashi T, Imai K, Hollingsworth MA: Overexpression of MUC1 reconfigures the binding properties of tumor cells. Int J Cancer 2001, 94:783-791.

39. Agata N, Ahmad R, Kawano T, Raina D, Kharbanda S, Kufe D: MUC1 oncoprotein blocks death receptor-mediated apoptosis by inhibiting recruitment of caspase-8. Cancer Res 2008, 68:6136-6144.

40. Ren J, Agata N, Chen D, Li Y, Yu WH, Huang L, Raina D, Chen W, Kharbanda S, Kufe D: Human MUC1 carcinoma-associated protein confers resistance to genotoxic anticancer agents. Cancer Cell 2004, 5:163-175.

41. Rancourt C, Matte I, Lane D, Piché A: The role of MUC16 mucin (CA125) in the pathogenesis of ovarian cancer. In Ovarian cancer: basic science perspective. Volume 1. 1st edition. Edited by Farghaly SA. Croatia: InTech; 2012:67-84.

42. Goncharenko-Khaider N, Lane D, Matte I, Rancourt C, Piché A: Biological significance of apoptosis in ovarian cancer: TRAIL therapeutic targeting In Ovarian cancer: a clinical and translational update. Volume 1. 1st edition. Edited by Diaz-Padilla I. Croatia: InTech; 2013:227-250. 
43. Lakshmanan I, Ponnusamy MP, Das S, Chakraborty S, Haridas D, Mukhopadhyay P, Lele SM, Batra SK: MUC16 induced rapid G2/M transition via interactions with JAK2 for increased proliferation and anti-apoptosis in breast cancer cells. Oncogene 2012, 31:805-817.

44. Dodier $\mathrm{P}$, Piché $\mathrm{A}: \mathrm{BCl}-\mathrm{X}(\mathrm{L})$ is functionally non-equivalent for the regulation of growth and survival in human ovarian cancer cells. Gynecol Oncol 2006, 100:254-263.

doi:10.1186/1471-2407-14-234

Cite this article as: Matte et al:: MUC16 mucin (CA125) attenuates

TRAIL-induced apoptosis by decreasing TRAIL receptor R2 expression and increasing C-FLIP expression. BMC Cancer 2014 14:234.

\section{Submit your next manuscript to BioMed Central and take full advantage of:}

- Convenient online submission

- Thorough peer review

- No space constraints or color figure charges

- Immediate publication on acceptance

- Inclusion in PubMed, CAS, Scopus and Google Scholar

- Research which is freely available for redistribution 